\title{
Utilization and Impact of Complementary and Alternative Medicines in Symptomatic Autoimmune Hepatitis Patients
}

\author{
Kayla Gelow $^{1} \cdot$ Sai Chalasani ${ }^{1} \cdot$ Kelsey Green ${ }^{1} \cdot$ Craig Lammert $^{1}$ (D)
}

Received: 15 March 2021 / Accepted: 11 June 2021 / Published online: 23 June 2021

(c) The Author(s) 2021

\begin{abstract}
Background Complementary and alternative medicine (CAM) use has become increasingly common. It is also prevalent in patients with chronic liver disease, but the scope, depth, and safety of use is not well known.

Aims This study aimed to evaluate the prevalence and patterns of CAM use in autoimmune hepatitis (AIH) patients.

Methods Electronic invitation to complete a 22 item CAM-specific questionnaire was posted weekly to well-established AIH Facebook communities (combined membership of 4700 individuals) during a 6-week study period. Age $\geq 18$ years and AIH diagnosis made by a treating physician were the eligibility criteria.

Results The prevalence of ever CAM use among participants was $56.4 \%$, and nearly $42 \%$ used CAM after AIH diagnosis. Among those reporting CAM use after diagnosis, 53.7\% (51/95) indicated CAM was used to mitigate AIH-related phenomenon, most often targeting liver inflammation/fibrosis (67.7\%), fatigue (51\%), joint pain (47.1\%), and sleep issues (45.1\%). Most frequent physical CAM strategies were exercise (49.5\%) and yoga (34\%), whereas most frequent consumable CAM included healthier eating (45.3\%), cannabidiol preparations (45.3\%), and probiotics (44.3\%). Seventy-five percent reported that CAM improved AIH symptoms and no severe adverse events were reported.

Conclusions CAM use in AIH patients is prevalent, yet providers have historically failed to document their patient's CAM strategies. Beyond inherent drug-induced liver injury risk, drug-drug interactions remain a concern and could alter baseline immunosuppression levels in AIH. Despite a majority found CAM approaches that improved targeted symptoms, all were unable to alter the course of chronically prescribed medications by physicians.
\end{abstract}

Keywords Supplement $\cdot$ Complementary and alternative medicine $\cdot$ CAM $\cdot$ Autoimmune hepatitis $\cdot$ AIH

\section{Introduction}

Complementary and alternative medicine (CAM) products and strategies have increased in popularity across North America, Europe, and Australia [1-3]. CAM includes natural health products such as vitamins, homeopathic remedies, exercise, diet, mental health, and herbal medicines. In the United States, CAM use rates among the general population have risen from $32.3 \%$ in 2002 to $38 \%$ in 2007 [1] and more

Kayla Gelow and Sai Chalasani have contributed equally to the work.

Craig Lammert

clammert@iu.edu

1 Division of Gastroenterology and Hepatology, Department of Medicine, Indiana University School of Medicine, 702 Rotary Circle, Suite 225, Indianapolis, IN 46202, USA recent estimates have shown over $50 \%$ of patients requiring healthcare have used CAM either in conjunction with or separate from conventional healthcare [4].

CAM use is prevalent in patients with chronic liver disease (CLD) but is not well studied. For instance, CAM use among CLD patients in the United States (U.S.) has been observed in $41 \%$ compared to $33 \%$ of patients without CLD $[1,5]$. Furthermore, CAM use among CLD patients has been reported higher outside the United States, as a Taiwanese study showed $66 \%$ of CLD used CAM during the past ten years $[6,7]$. Concerningly, underlying chronic liver disease may increase risk of toxicity or adverse side effects of CAM. Altered drug metabolism [8], increased risk of drug-induced liver injury (DILI) [9], and concurrent medications often utilized in CLD patients are possible factors but are challenging to predict given a wide array of available products and often undisclosed CAM use [10]. 
Despite the increase in CAM use, most physicians remain poorly educated about the variability and range of products and unaware of their own patient's CAM practices. Physicians do not routinely collect patient CAM history at office visits, and less than $23 \%$ disclose their CAM use when interviewed [11]. Inadequate CAM knowledge and physician ignorance of patient use can severely affect patients' health, as some CAM have well documented adverse side effects or interactions with prescription medication $[5,12,13]$.

A rare chronic liver disease, autoimmune hepatitis $(\mathrm{AIH})$, has been suggested to have increasing incidence and prevalence in several regions. Multiple therapeutic options are available for liver-specific inflammation observed in patients AIH, yet patients continue to suffer from poorly-controlled extrahepatic symptoms (i.e., fatigue, insomnia, anxiety, depression, and pain) [14]. We previously observed that $25 \%$ of AIH patients have used cannabidiol (CBD) to treat these symptoms [4], yet utilization of CAM outside CBD is unknown. We aimed to examine the overall use of CAM strategies among AIH patients using a large, well-established online cohort. We hypothesized that CAM use is prevalent in AIH patients and patterns of use can help identify unmet therapeutic needs in AIH patients and possible drug-drug interactions.

\section{Methods}

\section{AlH Patients}

A cross-sectional survey study using the Autoimmune Hepatitis Association (AIHA) Facebook communities (www. facebook.com) was conducted over six weeks (Fig. 1). The AIHA communities included a public community page and a member-only group. We previously described this approach for collecting patient-reported disease attributes [12] as well as recruitment to an ongoing AIH biorepository at Indiana University [8]. At the time of the study, the membership of a private AIHA community was over 2800 individuals. No membership numbers are associated with the public AIHA community group, yet the number of registered members to the AIHA was nearly 1900 at the time of the study. A digital invitation to complete a CAM survey was posted in each group weekly over the study duration (June-July 2020). The invitation included a hyperlink directed to an IRB-approved REDCap database for data collection.

\section{CAM Survey Tool}

The CAM questionnaire was composed of 22 questions (Supplementary Table 1) and collected participant

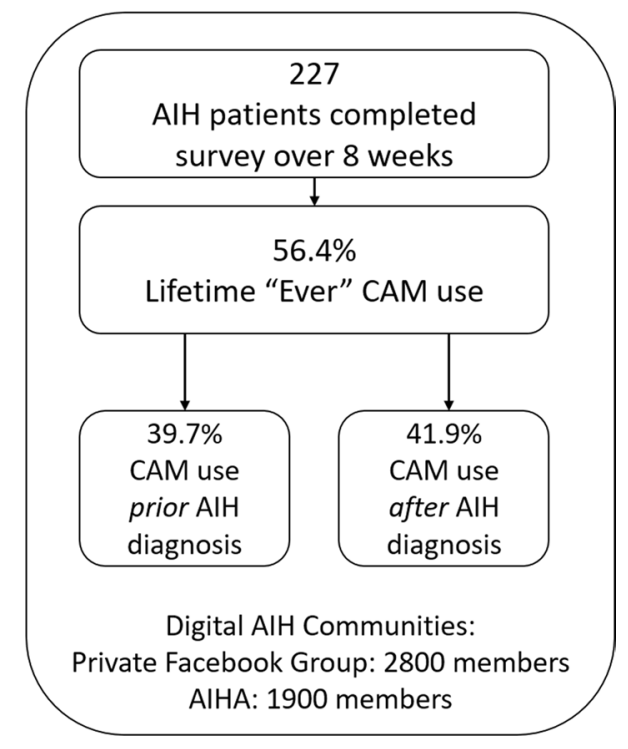

Fig. 1 CAM survey completion among AIH patients in online patient communities

demographics, AIH disease characteristics, CAM history and current use, and CAM-related adverse events. Categorical responses were multiple-choice, but also included few short answer responses (i.e., specific supplement utilized). CAM use was defined as use of at least one natural health product such as vitamins, homeopathic remedies, exercise, diet, mental health, and herbal medicines. Participants were required to be aged $\geq 18$ years and previously were diagnosed with AIH by a physician.

Adverse events (AE) were defined by the Food and Drug Administration's (FDA) Code of Federal Regulations (CFR) Title 21 as any unfavorable or unintended symptom temporarily associated with the use of CAM [15]. Severe adverse events (SAE) were defined as an AE that resulted in one of the following: life-threatening, required hospitalization, or resulted in disability.

\section{Statistical Analysis}

We employed a logistic regression model (CI 95\% and $\mathrm{p}$-value $<0.05$ ) for categorical variables, and the outcome was CAM use. Cofounders were sociodemographic (age, sex, educational level, country, race, and socioeconomic index). Continuous variables were summarized as means, and standard deviations and $\mathrm{p}$ values were obtained using the Student's T test. P values for discrete variables were obtained from the Chi-Square test. Adjusted Odd Ratios were obtained for each variable. Survey data were analyzed using SPSS 25 software. 


\section{Results}

\section{Patient Demographics and AlH History}

A total of 227 AIH patients successfully completed the study questionnaire, and 56.4\% reported ever using CAM. The majority of participants were female $(92.9 \%)$ and Caucasian $(85.2 \%)$. The mean age at survey completion was 50.1 years and the mean duration of AIH was 6.1 years. In the most recent liver biopsy, $23.5 \%$ of participants reported no fibrosis, $43.7 \%$ had early fibrosis (stage I/II), and $27.8 \%$ had advanced fibrosis (stage III/IV). Only $5.0 \%$ of participants reported never having a liver biopsy. Most (50.1\%) reported current treatment of AIH with a thiopurine (azathioprine, $44.5 \%$; 6-mercaptopurine: 5.7\%), yet nearly half of participants also reported treatment with a corticosteroid (prednisone 37\%, budesonide 14\%). Many participants were employed (45.5\%) and had a bachelor's degree (25.9\%) with private medical insurance (65.0\%) (Table 1).

\section{Demographics of CAM Use}

In total, 128 (56.4\%) AIH patients reported ever using CAM (Table 1). There was no difference between groups ever/ never using CAM according to demographics such as age, race, ethnicity or region. Furthermore, no AIH disease characteristics (duration, fibrosis level, current therapy) or type of insurance held were different across CAM use groups. However, participants that ever-used CAM were more often employed (46.9\% vs $43.5 \%)$ or retired $(20.3 \%$ vs $15.2 \%$, $\mathrm{p}=0.026)$ as well as more likely to have a Bachelor's $(28.9 \%$ vs $22.2 \%$ ) or Graduate degree ( $28.9 \%$ vs $16.2 \%, \mathrm{p}=0.012)$ compared to participants never using CAM.

\section{Timing and Indication for CAM}

Prior to the diagnosis of AIH, 90 (39.6\%) participants reported CAM use for a variety of reasons: general health (61.1\%), joint support (26.7\%), immune support (18.9\%), weight loss (17.8\%), sedative (14.4\%), gastrointestinal symptoms (14.4\%), depression/anxiety (12.2\%), body building (2.2\%), sexual performance (1.1\%), and other (7.8\%). After the diagnosis of AIH, 95 (41.9\%) cases reported CAM used for general health (38.6\%), pain relief (25.5\%), immune support $(25 \%)$, depression/anxiety (15.9\%), sedative (11.4\%), energy booster (11.4\%), gastrointestinal symptoms (6.8\%), weight loss (4.5\%), and other (13.6\%). Among those with CAM use after AIH diagnosis, 51 (53.7\%) indicated CAM use was directed at treating AIH-related phenomenon: $67.7 \%$ for liver-specific concerns (fibrosis/inflammation), $45.1 \%$ for sleep issues, $47.1 \%$ for joint pain, $51 \%$ for fatigue, $13.7 \%$ for itch, and $3.9 \%$ other (Table 2).

\section{Specific CAM Use Among Participants}

CAM use after AIH diagnosis was reported among 95 (41.9\%) participants and the most frequent CAM strategies across all categories included exercise (49.5\%), healthier eating (45.3\%), and cannabidiol (CBD) preparations (45.3\%) (Table 3). The most prevalent physical strategies included exercise (49.5\%), yoga (34\%), massage (26\%), and chiropractic therapy (26\%). Prevalent dietary modifications included healthier eating (45.3\%), low carb diets (18.5\%), vegetarian diets (12.3\%). Prevalent consumable CAM included CBD preparations (45.3\%), probiotics (44.3\%), multivitamins (32.9\%), melatonin (30.9\%), vitamin D (29.8\%), and milk thistle (21.6\%). Among all CAM users after AIH diagnosis, 79\% found at least one CAM strategy improved the targeted symptom or indication.

Among AIH patients using CAM to treat AIH-related phenomenon, liver concerns (fibrosis/inflammation) were the most common. Forty-one participants $(41 / 51,80.3 \%)$ most frequently utilized milk thistle, apple cider vinegar, multivitamins, ginger, turmeric, $\mathrm{CBD}$, and a healthier diet to improve liver concerns. A majority (75\%) stated that these CAM strategies relieved associated complaints. Fatigue (40/51, 78\%) was treated with B-complex vitamins, meditation, and coffee (89\% reported improvement). General pain $(36 / 51,70.6 \%)$ was treated with CBD and massage (85\% reported improvement). Sleep disturbances (33/51, $64.7 \%$ ) were treated with melatonin, yoga, and meditation (95\% reported improvement). Finally, itch (10/51, 19.6\%) was treated with over-the-counter diphenhydramine $(53 \%$ reported improvement). No participants reported that CAM was able to reduce or eliminate their current doctor prescribed treatment regimens for any other these concerns.

\section{Adverse Events Related to CAM}

Only five participants reported an adverse outcome related to CAM use. Among these, AIH disease duration ranged from four to thirteen years, and current age ranged from 30 to 69 years old. All five participants were female. Stage of fibrosis included no fibrosis at the last biopsy to cirrhosis. Adverse events attributed to CBD preparations were reported by three participants (2.3\%): hunger (1), dry mouth (1), red eyes (1), euphoria (1), and itchiness (1). Two participants reported side effects are significant enough to seek their physician's advice, but no emergency room visits, or hospitalizations were reported. 
Table 1 Demographics and selected characteristics of AIH participants and CAM use cohorts

\begin{tabular}{|c|c|c|c|c|}
\hline & AIH cases $(N=227)$ & $\begin{array}{l}\text { Ever used CAM } \\
(n=128)\end{array}$ & $\begin{array}{l}\text { Never used CAM } \\
(n=99)\end{array}$ & $p$ value* \\
\hline CAM ever, $\%$ & $56.40 \%$ & $100 \%$ & $0 \%$ & \\
\hline Age of survey completion (years) & $50.1(13.3)$ & $49.9(13.1)$ & $50.4(13.5)$ & 0.764 \\
\hline AIH disease duration (years) & $6.1(2.6)$ & $43.2(15.3)$ & $45.1(14.7)$ & 0.368 \\
\hline Gender, $\%$ female & $92.50 \%$ & $94.50 \%$ & $89.90 \%$ & 0.189 \\
\hline \multicolumn{5}{|l|}{ Race } \\
\hline Caucasian & $88.60 \%$ & $89.80 \%$ & $87.80 \%$ & \multirow[t]{4}{*}{0.42} \\
\hline African-American & $2.60 \%$ & $1.60 \%$ & $4.00 \%$ & \\
\hline Multiple & $1.80 \%$ & $2.30 \%$ & $1.00 \%$ & \\
\hline Other & $4.80 \%$ & $7.00 \%$ & $6.10 \%$ & \\
\hline \multicolumn{5}{|l|}{ Ethnicity } \\
\hline Hispanic & $3.50 \%$ & $3.10 \%$ & $4 \%$ & 0.92 \\
\hline \multicolumn{5}{|l|}{ Continent } \\
\hline North America & $84.10 \%$ & $85.20 \%$ & $82.80 \%$ & \multirow[t]{3}{*}{0.603} \\
\hline Europe & $12.30 \%$ & $12.50 \%$ & $12.10 \%$ & \\
\hline Australia & $3.10 \%$ & $2.30 \%$ & $4.00 \%$ & \\
\hline \multicolumn{5}{|l|}{ North America } \\
\hline USA & $81.40 \%$ & $81.30 \%$ & $81.80 \%$ & \multirow[t]{2}{*}{0.212} \\
\hline Canada & $3.10 \%$ & $3.90 \%$ & $2.00 \%$ & \\
\hline \multicolumn{5}{|l|}{ Gross household incomelyear } \\
\hline$<\$ 20,000$ & $7.90 \%$ & $7.00 \%$ & $9.10 \%$ & \multirow[t]{5}{*}{0.392} \\
\hline$\$ 20,001-\$ 50,000$ & $22.90 \%$ & $21.90 \%$ & $24.20 \%$ & \\
\hline$\$ 50,001-\$ 100,000$ & $35.70 \%$ & $32.80 \%$ & $39.40 \%$ & \\
\hline$\$ 100,001-\$ 150,000$ & $18.90 \%$ & $19.50 \%$ & $18.20 \%$ & \\
\hline$>\$ 150,000$ & $13.70 \%$ & $18.00 \%$ & $8.10 \%$ & \\
\hline \multicolumn{5}{|l|}{ Employment } \\
\hline Employed & $45.40 \%$ & $46.90 \%$ & $43.40 \%$ & \multirow[t]{5}{*}{0.026} \\
\hline Retired & $18.10 \%$ & $20.30 \%$ & $15.20 \%$ & \\
\hline Unemployed & $15.40 \%$ & $13.30 \%$ & $18.20 \%$ & \\
\hline Part-Time & $11.90 \%$ & $7.00 \%$ & $18.20 \%$ & \\
\hline Self-Employed & $9.30 \%$ & $12.50 \%$ & $5.10 \%$ & \\
\hline \multicolumn{5}{|l|}{ Level of education } \\
\hline Some college & $29.10 \%$ & $28.10 \%$ & $30.30 \%$ & \multirow[t]{6}{*}{0.012} \\
\hline Bachelor''s degree & $26 \%$ & $28.90 \%$ & $22.20 \%$ & \\
\hline Graduate degree & $23.30 \%$ & $28.90 \%$ & $16.20 \%$ & \\
\hline GED & $11.90 \%$ & $6.30 \%$ & $19.30 \%$ & \\
\hline Technical school & $6.10 \%$ & $7.80 \%$ & $11.10 \%$ & \\
\hline Some high school & $0.40 \%$ & $0.00 \%$ & $1.00 \%$ & \\
\hline \multicolumn{5}{|l|}{ Medical insurance } \\
\hline Private & $64.80 \%$ & $71.10 \%$ & $56.60 \%$ & \multirow[t]{4}{*}{0.15} \\
\hline Medicaid & $18.90 \%$ & $15.60 \%$ & $23.20 \%$ & \\
\hline Medicare & $11 \%$ & $8.60 \%$ & $14.10 \%$ & \\
\hline Uninsured & $5.30 \%$ & $4.70 \%$ & $6.10 \%$ & \\
\hline \multicolumn{5}{|l|}{ Fibrosis on biopsy } \\
\hline F0 & $23.30 \%$ & $21.10 \%$ & $26.30 \%$ & \multirow[t]{6}{*}{0.074} \\
\hline $\mathrm{F} 1$ & $16.30 \%$ & $14.80 \%$ & $18.20 \%$ & \\
\hline $\mathrm{F} 2$ & $26.20 \%$ & $32.80 \%$ & $18.20 \%$ & \\
\hline F3 & $15.40 \%$ & $12.50 \%$ & $19.20 \%$ & \\
\hline $\mathrm{F} 4$ & $12.30 \%$ & $13.30 \%$ & $11.10 \%$ & \\
\hline No biopsy completed & $4.80 \%$ & $5.50 \%$ & $4.00 \%$ & \\
\hline
\end{tabular}


Table 1 (continued)

AIH cases $(N=227)$

Ever used CAM

$(n=128)$

Current immunosuppression

Prednisone

Budesonide (Entocort)

Azathioprine (Imuran)—thiopurines

6-Mercaptopurine (6MP)

Mycophenolate mofetil (CellCept, Myfortic)

Tacrolimus (Prograf)

Naltrexone (Narcan)

No medications

\begin{tabular}{llll}
$37.00 \%$ & $32.80 \%$ & $42.40 \%$ & 0.137 \\
$14 \%$ & $14.10 \%$ & $14.10 \%$ & 0.986 \\
$44.40 \%$ & $58.6 \%$ & $48.5 \%$ & 0.13 \\
$5.70 \%$ & $4.7 \%$ & $7.1 \%$ & 0.443 \\
$15.40 \%$ & $12.5 \%$ & $19.2 \%$ & 0.166 \\
$3.10 \%$ & $0.8 \%$ & $6.1 \%$ & 0.023 \\
$3.04 \%$ & $3.1 \%$ & $0.0 \%$ & 0.204 \\
$17.60 \%$ & $23.3 \%$ & $18.2 \%$ & 0.106 \\
\hline
\end{tabular}

${ }^{*} p$ value, comparison of ever used CAM versus never used CAM

Table 2 Demographics and selected characteristics of $\mathrm{AIH}$ participants to use CAM prior and after AIH diagnosis

\begin{tabular}{lll}
\hline CAM category & \multicolumn{2}{l}{ CAM study cohort $(N=227)$} \\
\cline { 2 - 3 } & $\begin{array}{l}\text { CAM use prior AIH } \\
\text { diagnosis }(N=90)\end{array}$ & CAM use after AIH diagnosis $(N=95)$ \\
& & CAM use not targeting AIH symptoms $(N=44)$ \\
\hline Body building & $2(2.2 \%)$ & 0 \\
Depression/anxiety & $11(12.2 \%)$ & $7(15.9 \%)$ \\
Energy booster & $13(14.4 \%)$ & $5(11.4 \%)$ \\
Gastrointestinal symptoms & $13(14.4 \%)$ & $3(6.8 \%)$ \\
General health/well being & $55(61.1 \%)$ & $17(38.6 \% \%)$ \\
Immune support & $17(18.9 \%)$ & $11(25 \%)$ \\
Joint support/arthritis & $24(26.7 \%)$ & $5(11.4 \%)$ \\
Pain relief & $13(14.4 \%)$ & $9(25.5 \%)$ \\
Sedative/sleep aid & $26(28.8 \%)$ & $5(11.4 \%)$ \\
Sexual performance & $1(1.1 \%)$ & 0 \\
Weight loss & $16(17.8 \%)$ & $2(4.5 \%)$ \\
Other & $7(7.8 \%)$ & $6(13.6 \%)$ \\
Liver concerns (inflammation, & & CAM use targeting AIH symptoms $(N=51)$ \\
fibrosis) & & $33(67.7 \%)$ \\
Sleep issues & & $23(45.1 \%)$ \\
Joint pain & & $24(47.1 \%)$ \\
Fatigue & & $26(51 \%)$ \\
Itch & & $2(13.7 \%)$ \\
Other & & \\
\hline
\end{tabular}

\section{Discussion}

CAM use continues to increase in developed countries [1-3]. More recent estimates have shown more than 50\% of patients requiring healthcare have used CAM either in conjunction with or separate from conventional healthcare [4]. In this first ever detailed assessment of CAM use in AIH patients, we observed that over half $(56 \%)$ of all participants reported ever using CAM, and $42 \%$ had used CAM after AIH diagnosis. Employed or retired AIH patients with advanced educational degrees were more likely to use CAM compared to those unemployed or parttime workers with a GED or technical training. The most frequent AIH-related phenomenon targeted by consumable and physical CAM was liver fibrosis/inflammation, fatigue, joint pain, and sleep issues. The most common consumable CAM agents included CBD preparations, healthier diets, physical activity, probiotics, multivitamins, melatonin, and milk thistle. The most frequent physical CAM strategies included exercise, yoga, and acupuncture. Among all AIH patients using CAM for any indication after AIH 
Table 3 Prevalence of CAM use among AIH participants prior and after diagnosis

Prior AIH diag- $\quad$ After AIH diag$\operatorname{nosis}(N=90)(\%) \operatorname{nosis}(N=95)$

$(\%)$

Vitamins and minerals

\begin{tabular}{|c|c|c|}
\hline CBD oil & 12.20 & 45.30 \\
\hline Probiotics & 13.30 & 44.30 \\
\hline Multivitamins & 35.50 & 32.90 \\
\hline Melatonin & 36.60 & 30.90 \\
\hline Vitamin D & 14.40 & 29.80 \\
\hline Milk thistle & 5.50 & 21.60 \\
\hline Calcium & 11.10 & 12.30 \\
\hline Apple cider vinegar & 0 & 12.30 \\
\hline Vitamin $\mathrm{C}$ & 12.20 & 8.20 \\
\hline Ginger & 1.10 & 6.20 \\
\hline B-Complex & 5.50 & 4.40 \\
\hline \multicolumn{3}{|l|}{ Dietary modifications } \\
\hline Healthier eating & 51.10 & 45.30 \\
\hline Low carb diet & 4.40 & 18.50 \\
\hline Vegetarian diet & 13.30 & 12.30 \\
\hline Keto diet & 8.90 & 11.30 \\
\hline Paleo diet & 5.50 & 10.30 \\
\hline Vegan diet & 4.40 & 8.20 \\
\hline Juicing & 15.50 & 8.20 \\
\hline Detoxification & 4.40 & 7.20 \\
\hline Essential oils & 23.30 & 20.60 \\
\hline \multicolumn{3}{|l|}{ Physical treatment } \\
\hline Exercise & 82.20 & 49.50 \\
\hline Massage & 53.30 & 26.00 \\
\hline Yoga & 37.80 & 34.00 \\
\hline Chiropractic & 40.00 & 26.80 \\
\hline Acupuncture & 26.70 & 20.60 \\
\hline Professional physical therapy & 36.70 & 12.40 \\
\hline Tai Chi & 8.90 & 5.10 \\
\hline \multicolumn{3}{|l|}{ Mental therapy } \\
\hline Meditation & 28.90 & 27.80 \\
\hline Counseling & 21.10 & 17.50 \\
\hline Spiritual healing & 3.30 & 7.20 \\
\hline \multicolumn{3}{|l|}{ Any CAM improved symptoms } \\
\hline Yes & 70 & 79 \\
\hline No & 30 & 21 \\
\hline
\end{tabular}

Reporting therapies with prevalence $>5 \%$

diagnosis, $79 \%$ reported improved targeted symptoms, but none could reduce the need for physician-prescribed medications. Fortunately, no severe adverse events or hospitalizations were reported, and only 5 participants reported adverse reactions and two emergency room evaluations.

AIH cases in our study reported a generally similar frequency of CAM use compared to other autoinflammatory conditions such as IBD (41\%) [16] and systemic lupus erythematosus (50\%) [17] and the U.S. population (50\%) $[18,19]$. However, our results differ from other chronic illnesses; patients with breast cancer reported $96.5 \%$ ever using CAM and $86.1 \%$ after diagnosis [20]. In a previous study, we observed CBD preparations were used in $25 \%$ of AIH patients to improve factors impacting quality of life, often targeting pain and sleep, and fatigue [10]. Here, we found AIH patients with lower household incomes were more likely to use CBD. This was opposite of our observation in the current study, as income did not differ between consumers of all CAM (Table 1). In fact, participants that have utilized CAM were more likely to have received higher education and be currently employed or retired compared to never CAM users. Other studies have suggested higher education and current employment do positively correlate with CAM use but may indicate subgroups with more resources for physical CAM [21, 22]. Often, physical CAM strategies (i.e., yoga, acupuncture, and chiropractor) are costlier and require a trained practitioner. In contrast, consumable CAM (i.e., CBD and vitamins) may have overall lower costs given widespread availability.

Most study participants (75\%) reported that CAM strategies relieved targeted complaints. The most frequent CAM strategies that improved symptoms were physical activity (49.5\%) (i.e., exercise, yoga), healthier eating (45.3\%), and CBD preparations (45.3\%). Recent studies have shown that patients with an autoimmune illness may be able to increase physical fitness and quality of life with a structured exercise training regime. A study examining a 12 -week resistance training program in multiple sclerosis patients found that exercise improved voluntary isometric contraction and muscle power [23]. Other studies have found correlations between healthy eating and autoimmune disease management. A recent study found that patients following the autoimmune protocol diet for treating inflammatory bowel disease (IBD) in conjunction with IBD medication, resulted in reduced symptoms and in some cases potentiated clinical remission [24].

Our study revealed that CAM use for AIH-related symptoms was most often targeting fatigue, pain, sleep disturbance, and itch, with over $78 \%$ of AIH patients observing improvement in these areas with at least one CAM strategy. Recent studies have found similar results of CAM use reducing symptoms of fatigue, pain, and insomnia. CAM use in cancer patients has supported acupuncture, massage, yoga, meditation, and relaxation training to help alleviate fatigue [25]. In this same study, multivitamins were ineffective at reducing cancer-related fatigue [25]. Other studies researching CAM's efficacy in relation to pain and insomnia in patients with chronic illness found that CAM was helpful in reducing pain (i.e., exercise, acupuncture, and chiropractic medicine) and decreasing sleep disturbances (i.e., melatonin, meditation, and yoga) [26, 27]. Even though AIH 
patients in our study reported improvement in AIH-related symptoms with CAM use, no patients reported reduction or cessation of chronically prescribed medications. Numerous studies suggest attempts to eliminate chronically prescribed medications in favor of CAM are an ultimate risk to patient outcomes. However, when CAM is used in conjunction with prescription medication regimens, data supports CAM may be able to improve disease outcomes and patient quality of life [23-27].

FDA-approved medications have pharmacokinetic data that can provide theoretical drug-induced liver injury (DILI) risk among patients with cirrhosis or hepatic impairment. Yet, these types of data are largely unavailable for consumed CAM. Beyond this, CAM products are a substantial risk for DILI even among healthy individuals, as nutritional supplements account for $20 \%$ of hepatotoxicity cases in the U.S. [18]. Although there is limited data to suggest patients with cirrhosis are at higher risk of DILI, the dose of medication and extent of hepatic metabolism has correlated with DILI $[28,29]$. Nearly $28 \%$ of study participants in our study reported advanced fibrosis at most recent liver biopsy. Advanced liver fibrosis in AIH cases did not seem to be a deterrent to CAM use as we observed similar proportions of fibrosis levels across ever versus never CAM groups (Table 1). It is challenging to comment on DILI risk among participants in this study, as there was a wide variability of products, preparations, and limited pharmacokinetic data. Further, the bioavailability of a compound is a related risk factor for DILI, yet this aspect is often challenging to predict in patients with cirrhosis [9].

The safety of CAM in AIH may also be challenged by innate liver disease and concurrent medication use. For instance, CBD is a potent inhibitor of CYP3A4 and 2C19 and both corticosteroids (prednisone or budesonide) and calcineurin inhibitors (such as tacrolimus or cyclosporine) undergo metabolism via CYP3A4, thus pose a possible risk to $51 \%$ of patients currently taking corticosteroids and $3.1 \%$ using tacrolimus in our study. Inhibition of CYP3A4 and $2 \mathrm{C} 19$ by CBD may increase drug levels and/or potentiate side effects of these immunosuppressive regimens. Clinicians and AIH patients taking corticosteroids, tacrolimus, or cyclosporine should approach CBD with caution and monitor for adverse effects or toxicity [10].

We were reassured that only 5 participants reported adverse events, of which 2 required a dedicated physician's visit, but no hospitalizations or severe adverse events occurred. Further given this safety profile and a relatively positive response to a variety of CAM strategies (i.e., 79\% improvement of symptoms targeted after AIH diagnosis), $\mathrm{CAM}$, in general, is worthy of further dedicated investigational studies of AIH. These findings are pivotal, as healthrelated quality of life in AIH is significantly reduced [21, 22]. The frequent use of CAM to reduce AIH symptoms highlights critical treatment gaps that are increasingly prevalent in this rare disease.

We readily admit to the limitations of this study, much of which is rooted in the patient-reported aspects of $\mathrm{AIH}$ and memory recall bias of historical CAM use. However, $\mathrm{AIH}$ patients have exhibited excellent diagnosis agreements compared to their medical records [8]. This limitation also provides strength, as the utilization of anonymity via this survey platform is likely to promote more honest responses to the spectrum of CAM use. Furthermore, the standardization of the definition of the terms "alternative, traditional or complementary medicine" is also a factor that makes comparisons with studies difficult. A limitation of the present study was asking about homeopathy, acupuncture and medicinal plants, and herbal medicines. These terms may vary in meaning, such as "medicinal plants" and "herbal medicines": according to WHO document, published in 2013, have different meanings [30]. The study's strength is it is the first to collect data about the prevalence and safety of CAM use in a representative survey of AIH patients.

In summary, CAM use in AIH patients is associated with socioeconomic status, but not demographic or diseaserelated factors. AIH patients were often able to find a CAM strategy (CBD, healthy eating, exercise, yoga, meditation, and vitamins) to improve AIH-related symptoms (fatigue, sleep issues, joint pain, fatigue, itch) and overall quality of life. Though a majority saw improvement of symptoms, patients did not reduce or eliminate prescribed medication regimens. Given minimal adverse events were reported and a positive response to a variety of CAM strategies (i.e., 79\% improvement of symptoms targeted after AIH diagnosis), CAM seems worthy of further dedicated investigational studies of AIH. Based on these conclusions, a hypothesis for future research would be examining the physiological efficacy of CAM in AIH and domains related to improved quality of life.

Supplementary Information The online version contains supplementary material available at https://doi.org/10.1007/s10620-021-07112-0.

Funding Funding was provided by National Institute of Diabetes and Digestive and Kidney Diseases (Grant No. DK114561).

\section{Declarations}

Conflict of interest The authors declare that they have no conflict of interest.

Open Access This article is licensed under a Creative Commons Attribution-NonCommercial 4.0 International License, which permits any non-commercial use, sharing, adaptation, distribution and reproduction in any medium or format, as long as you give appropriate credit to the original author(s) and the source, provide a link to the Creative Commons licence, and indicate if changes were made. The images or other third party material in this article are included in the article's Creative 
Commons licence, unless indicated otherwise in a credit line to the material. If material is not included in the article's Creative Commons licence and your intended use is not permitted by statutory regulation or exceeds the permitted use, you will need to obtain permission directly from the copyright holder. To view a copy of this licence, visit http://creativecommons.org/licenses/by-nc/4.0/.

\section{References}

1. Henson JB, Brown CL, Chow S-C, Muir AJ. Complementary and alternative medicine use in United States adults with liver disease. J Clin Gastroenterol. 2017;51:564-570. https://doi.org/10.1097/ mcg.0000000000000617.

2. White CP, Hirsch G, Patel S, Adams F, Peltekian KM. Can J Gastroenterol. Published 2007. https://www.hindawi.com/journals/ cjgh/2007/231636/.

3. Del Prete A, Scalera A, Iadevaia MD, et al. Herbal Products: Benefits, Limits, and Applications in Chronic Liver Disease. Evidence-Based Complementary and Alternative Medicine. Published September 6, 2012. https://www.hindawi.com/journ als/ecam/2012/837939/. Accessed December 14, 2020.

4. Picardo S, Altuwaijri M, Devlin SM, Seow CH. Complementary and alternative medications in the management of inflammatory bowel disease. Ther Adv Gastroenterol. 2020;13:175628482092755. https://doi.org/10.1177/1756284820 927550.

5. Bruguera M, Barrera JM, Ampurdanés S, Forns X, Sánchez Tapias JM. Use of complementary and alternative medicine in patients with chronic hepatitis C. Medicina Clinica. 2004;122:334-335. https://doi.org/10.1016/s0025-7753(04)74226-8.

6. Liu CY, Chu JY, Chiang JH et al. utilization and prescription patterns of traditional Chinese medicine for patients with hepatitis $\mathrm{C}$ in Taiwan: a population-based study. BMC Complement Altern Med 2016;16:397.

7. Yang ZC, Yang S-H, Yang S-S, Chen D-S. A hospital-based study on the use of alternative medicine in patients with chronic liver and gastrointestinal diseases. Am J Chin Med. 2002;30:637-643. https://doi.org/10.1142/S0192415X02000569.

8. Lammert C, Imler T, Teal E et al. Patients with chronic liver disease suggestive of nonalcoholic fatty liver disease may be at higher risk for drug-induced liver injury. Clin Gastroenterol Hepatol 2019;17:2814-2815.

9. Teschke R, Danan G. Drug-induced liver injury: Is chronic liver disease a risk factor and a clinical issue? Expert Opin Drug Metab Toxicol 2017;13:425-438.

10. Mathur K, Vuppalanchi V, Gelow K et al. Cannabidiol (CBD) consumption and perceived impact on extrahepatic symptoms in patients with autoimmune hepatitis. Dig Dis Sci 2020;65:322328. https://doi.org/10.1007/s10620-019-05756-7.

11. Schiano TD. Hepatotoxicity and complementary and alternative medicines. Clin Liver Dis. 2003;7:453-473. https://doi.org/10. 1016/s1089-3261(03)00030-8.

12. Philips CA, Augustine P, Rajesh S et al. Complementary and alternative medicine-related drug-induced liver injury in Asia. J Clin Transl Hepatol. 2019;7:263-274.

13. Seeff L, Lindsay K, Bacon B, Kresina T, Hoofnagle J. Complementary and alternative medicine in chronic liver disease. Hepatology. 2001;34:595-603. https://doi.org/10.1053/jhep.2001. 27445 .
14. Wong LL, Fisher HF, Stocken DD et al. The impact of autoimmune hepatitis and its treatment on health utility. Hepatology (Baltimore, Md). 2018;68:1487-1497. https://doi.org/10.1002/ hep.30031.

15. FDA. CFR - Code of Federal Regulations Title 21. www.acces sdata.fda.gov. Published 2016. https://www.accessdata.fda.gov/ scripts/cdrh/cfdocs/cfcfr/CFRSearch.cfm?CFRPart=21.

16. Koning M, Ailabouni R, Gearry RB et al. Use and predictors of oral complementary and alternative medicine by patients with inflammatory bowel disease: a population-based, case-control study. Inflamm Bowel Dis 2013;19:767-778.

17. Greco CM, Nakajima C, Manzi S. Updated review of complementary and alternative medicine treatments for systemic lupus erythematosus. Curr Rheumatol Rep 2013;15:378.

18. Navarro VJ, Khan I, Björnsson E et al. Liver injury from herbal and dietary supplements. Hepatology 2017;65:363-373.

19. Bailey RL, Gahche JJ, Lentino CV et al. Dietary supplement use in the United States, 2003-2006. J Nutr. 2011;141:261-266.

20. Greenlee H, Kwan ML, Ergas IJ et al. Complementary and alternative therapy use before and after breast cancer diagnosis: the pathways study. Breast Cancer Res Treat. 2009;117:653-665. https://doi.org/10.1007/s10549-009-0315-3.

21. Fjær EL, Landet ER, McNamara CL et al. The use of complementary and alternative medicine (CAM) in Europe. BMC Complement Med Ther 2020;20:108.

22. Astin JA. Why patients use alternative medicine: results of a national study. Jama 1998;279:1548-1553.

23. Medina-Perez C, De Souza-Teixeira F, Fernandez-Gonzalo R, De Paz-Fernandez JA. Effects of a resistance training program and subsequent detraining on muscle strength and muscle power in multiple sclerosis patients. NeuroRehabilitation 2014;34:523-530.

24. Konijeti GG, Kim N, Lewis JD et al. Efficacy of the autoimmune protocol diet for inflammatory bowel disease. Inflamm Bowel Dis. 2017;23:2054-2060. https://doi.org/10.1097/mib.0000000000 001221.

25. Finnegan-John J, Molassiotis A, Richardson A, Ream E. A systematic review of complementary and alternative medicine interventions for the management of cancer-related fatigue. Integr Cancer Ther. 2013;12:276-290. https://doi.org/10.1177/15347 35413485816.

26. Ghildayal N, Jo Johnson P, Evans RL, Jo Kreitzer M. Complementary and alternative medicine use in the US adult low back pain population. Glob Adv Health Med. 2016;5:69-78. https://doi.org/ 10.7453/gahmj.2015.104.

27. Gooneratne NS. Complementary and alternative medicine for sleep disturbances in older adults. Clin Geriatr Med. 2008;24:121-138. https://doi.org/10.1016/j.cger.2007.08.002.

28. Lammert C, Bjornsson E, Niklasson A et al. Oral medications with significant hepatic metabolism at higher risk for hepatic adverse events. Hepatology 2010;51:615-620.

29. Lammert C, Einarsson S, Saha C et al. Relationship between daily dose of oral medications and idiosyncratic drug-induced liver injury: search for signals. Hepatology 2008;47:2003-2009.

30. WHO. Guidelines on Good Agricultural and collection practices (GACP) for medicinal plantas. Vol 1. Geneve: World Health Organization Publications; 2013.

Publisher's Note Springer Nature remains neutral with regard to jurisdictional claims in published maps and institutional affiliations. 